\title{
Relationship between the amniotic fluid index at term and the perinatal outcome
}

\author{
Bhumika H. Dobariya*, Shree A. Jani, Ajesh N. Desai
}

Department of Obstetrics and Gynecology, GMERS Medical College, Sola, Ahmedabad, Gujarat, India

Received: 29 April 2020

Accepted: 28 May 2020

\section{*Correspondence:}

Dr. Bhumika H. Dobariya,

E-mail: bhumidobariya95@gmail.com

Copyright: (C) the author(s), publisher and licensee Medip Academy. This is an open-access article distributed under the terms of the Creative Commons Attribution Non-Commercial License, which permits unrestricted non-commercial use, distribution, and reproduction in any medium, provided the original work is properly cited.

\section{ABSTRACT}

Background: Amniotic fluid index (AFI) is commonly used to estimate amniotic fluid volume. A proper AFI is between 10 and 24 centimetres. If it is below $5 \mathrm{~cm}$, it is can represent oligohydramnios, and in case AFI is above 24 $\mathrm{cm}$, it can represent polyhydramnios. This study was undertaken to determine whether measuring AFI at term is useful in the prediction of perinatal outcome.

Methods: A prospective study of 250 pregnant women with gestational age between 37 and 42 weeks was conducted at Sola Civil Hospital. AFI was measured in each patient using the Phelan's technique and the perinatal outcome was studied. The results were analysed and presented in the form of tables and graphs.

Results: Total 250 patients were studied. Out of them, 33 patients $(13.2 \%)$ had AFI $<=5,215(86 \%)$ had AFI between 6 and 24; and 2 patients $(0.8 \%)$ had AFI $>=25.19$ out of $33(57.57 \%)$ patients with AFI $<=5$, had to undergo caesarean section, out of which, 12 caesarean sections $(63.15 \%)$ were taken for non-reassuring foetal status. $36.27 \%$ (78/215) of patients with AFI between 6 and 24 underwent caesarean section, out of which $38.46 \%$ (30/78) underwent caesarean section for non-reassuring foetal status.

Conclusions: In the presence of oligohydramnios, the rates of LSCS due to foetal distress, the occurrence of low Apgar score and of low birth weight are higher than in patients with normal liquor at term. Thus, measuring the amniotic fluid index at term can be helpful in the prediction of perinatal outcome.

Keywords: Amniotic fluid index, Caesarean section, Perinatal outcome, Phelan's technique, Term pregnancy

\section{INTRODUCTION}

Amniotic fluid is a transparent fluid surrounding the foetus. ${ }^{1}$ Amniotic fluid provides a protective milieu for the growing foetus, cushioning it against mechanical and biological injury. ${ }^{2,3}$ Amniotic fluid index (AFI) is commonly used to estimate amniotic fluid volume. A proper AFI is between 10 and 24 centimetres. $^{4}$ If it is below $5 \mathrm{~cm}$, it is can represent oligohydramnios, and in case AFI is above $24 \mathrm{~cm}$, it can represent polyhydramnios. 5 ,6 According to an investigation conducted by Morris et al, AFI $<5$ was positively correlated with asphyxia, C-section, low Apgar score and a $\mathrm{pH}>7$ of the umbilical cord. They also reported a positive correlation between AFI $<5$ and lengthened pregnancy and, therefore, suggested AFI for predicting prenatal problems. ${ }^{7}$ Objective of this study was to determine whether measuring the amniotic fluid index at term is useful in the prediction of perinatal outcome.

\section{METHODS}

A prospective study of 250 pregnant women with gestational age between 37 and 42 weeks, who came to the labour room with true labour pains, from $1^{\text {st }}$ April 2019 to $31^{\text {st }}$ August 2019, was conducted at Sola Civil Hospital, Sola, Ahmedabad, India. The women's history and clinical examination were recorded. The AFI was measured in each patient using the Phelan's technique and the perinatal outcome was studied. ${ }^{8}$ 
The perinatal outcome in terms of Meconium stained liquor, total number of LSCS done due to foetal distress, foetal birth weight, Apgar score at 1 minute and 5 minute, and NICU admissions within 24 hours, were noted. The results were analysed and presented in the form of tables and graphs.

\section{Inclusion criteria}

- Pregnant women with a singleton, non-anomalous foetus with gestational age between 37 and 42 weeks, who presented to the labour room with true labour pains with intact membranes in per vaginal examination, were included.

\section{Exclusion criteria}

- Women with known foetal or chromosomal anomalies, and/or placental anomalies were excluded from the study.

- Women with PROM, gestational diabetes, Rh incompatibility and/or multiple pregnancies, were excluded from the study.

\section{Statistical analysis}

Statistical analyses were performed using SPSS version 16.0 software (SPSS Inc, Chicago, IL). One-way analysis of variance (ANOVA) and Pearson's correlation tests were used in the statistical analysis.

\section{RESULTS}

Total 250 patients were studied. Out of them, 33 patients $(13.2 \%)$ had AFI $<=5,215(86 \%)$ had AFI between 6 and 24; and 2 patients $(0.8 \%)$ had AFI $>=25$ (Table 1$)$.

The mean age of the patients with AFI less than or equal to 5 , between 6 to 24 , and greater than 25 is 26.5 years, 26.8 years and 27.5 years, respectively (Table 2 ).

Total number of nulliparous patients with AFI $<=5$, AFI 6 to 24 and AFI >=25, are 22 out of $33(66.67 \%)$; 128 out of $215(59.53 \%)$; and 1 out of $2(50 \%)$, respectively (Table 2).

Table 1: Distribution according to AFI.

\begin{tabular}{|lll|}
\hline AFI & No. of patients (n) & Percentage \\
\hline$<=5$ & 33 & $13.2 \%$ \\
\hline $6-24$ & 215 & $86 \%$ \\
\hline$>=25$ & 2 & $0.8 \%$ \\
\hline Total & 250 & $100 \%$ \\
\hline
\end{tabular}

Table 2: Distribution according to the mean maternal age and number of nulliparous patients.

\begin{tabular}{|lll|}
\hline AFI & $\begin{array}{l}\text { Mean maternal } \\
\text { age (in years) }\end{array}$ & $\begin{array}{l}\text { No. of nulliparous } \\
\text { patients }\end{array}$ \\
\hline AFI $<=5$ & 26.5 & $22(66.67 \%)$ \\
\hline AFI 6-24 & 26.8 & $128(59.53 \%)$ \\
\hline AFI $>=25$ & 27.5 & $1(50 \%)$ \\
\hline
\end{tabular}

A total 19 out of $33(57.57 \%)$ patients with AFI $<=5$, had to undergo caesarean section, out of which, 12 caesarean sections $(63.15 \%)$ were taken for non-reassuring foetal status. $36.27 \%(78 / 215)$ of patients with AFI between 6 and 24 underwent caesarean section, out of which $38.46 \%$ (30/78) underwent caesarean section for nonreassuring foetal status (Table 3; row number 1 and 2).

Birth weight of less than $2.5 \mathrm{~kg}$ was observed in $54.54 \%$ of patients with AFI $<=5$, whereas it was observed in $21.86 \%$ of patients with AFI between 6 and 24 (Table 3; row number 4 ).

Apgar score at 1 minute was less than 7 in $36.36 \%$ of the patients with $\mathrm{AFI}<=5$ and $10.69 \%$ of the patients with AFI between 6 and 24 (Table 3; row number 5).

Apgar score at 5minutes was less than 7 in $6.06 \%$ of patients with AFI $<=5$ and $4.18 \%$ of patients with AFI between 6 and 24. (Table 3; row number 6). NICU admissions were observed in $84.84 \%$ of patients with AFI $<=5$ and in $69.30 \%$ of patients with AFI between 6 and 24 (Table 3; row number 7).

Table 3: Various perinatal outcomes according to the AFI of the patients.

\begin{tabular}{|lllll|}
\hline Row number & Parameter & $\begin{array}{l}\text { AFI }=5 \\
(\mathbf{n = 3 3})\end{array}$ & $\begin{array}{l}\text { AFI 6-24 } \\
(\mathbf{n = 2 1 5})\end{array}$ & $\begin{array}{l}\text { AFI>=25 } \\
(\mathbf{n = 2})\end{array}$ \\
\hline 1 & Total number of caesarean deliveries & $19(57.57 \%)$ & $78(36.27 \%)$ & $0(0 \%)$ \\
\hline 2 & Number of Caesarean for non-reassuring foetal status & $12(63.15 \%)$ & $30(38.46 \%)$ & $0(0 \%)$ \\
\hline 3 & Meconium stained liquor & $5(15.15 \%)$ & $34(15.8 \%)$ & $0(0 \%)$ \\
\hline 4 & Birth weight $<2.5 \mathrm{~kg}$ & $18(54.54 \%)$ & $47(21.86 \%)$ & $0(0 \%)$ \\
\hline 5 & Apgar score at 1 minute less than 7 & $12(36.36 \%)$ & $23(10.69 \%)$ & $0(0 \%)$ \\
\hline 6 & Apgar score at 5 minutes less than 7 & $2(6.06 \%)$ & $9(4.18 \%)$ & $0(0 \%)$ \\
\hline 7 & Admission to NICU & $28(84.84 \%)$ & $149(69.30 \%)$ & $0(0 \%)$ \\
\hline
\end{tabular}




\section{DISCUSSION}

In this study, the percentage of caesarean sections due to non-reassuring foetal status were higher in patients with AFI $<=5$, as compared to the patients with normal AFI. This was consistent with the findings by Chauhan et al, where their meta-analysis found that intrapartum AFI less than 5 was associated with increased risk of cesarean section for fetal distress (pooled relative risk $=1.7) .{ }^{9}$

In this study, the percentage of caesarean sections due to low birth weight, were higher in patients with $\mathrm{AFI}<=5$, as compared to the patients with normal AFI. These findings are similar to study by Locatelli et al, reported that in uncomplicated term pregnancies with oligohydramnios, the presence of an AFI less than 5 independently increased the risk for a SGA infant. ${ }^{10}$ Morris et al, found that $60 \%$ of babies were of LBW in the group with AFI less than 5, indicating that oligohydramnios had an association with growth restriction. ${ }^{11}$ A study by Rutherford et al, showed that when the AFI was less than $5(36 \%)$, pregnancies resulted in infants with intra uterine growth restriction (IUGR). ${ }^{12}$

The percentage of foetus with meconium stained liquor were similar $(\sim 15 \%)$ in Patients with AFI $<=5$ and AFI 6 to 24. A study conducted by Baron et al, showed that meconium stained amniotic fluid occurred significantly less often in the oligohydramnios group as compared to the normal AFI group. ${ }^{13}$ So, this study had different results as compared to this study. Many authors signified high ratios of meconium staining with AFI measurements below $5 \mathrm{~cm} .{ }^{14-16}$ A study by Voxman et al, concluded that there was no difference between the groups with regard to meconium-stained liquor, which has results similar to this study. ${ }^{17}$

Apgar score at 1 minute was less than 7 in $36.36 \%$ of the patients with $\mathrm{AFI}<=5$ and $10.69 \%$ of the patients with AFI between 6 and 24. Apgar score at 5minutes was less than 7 in $6.06 \%$ of patients with AFI $<=5$ and $4.18 \%$ of patients with AFI between 6 and 24. A study by Grubb et al, found the 1 minute Apgar score of less than 7 in $84 \%$ patients with AFI less than 5, as compared to $14 \%$ in the normal AFI group, which was highly significant $(\mathrm{p}=0.01) .{ }^{18}$ In the same study, the 5 -min score $<7$ was seen in $13 \%$ patients with AFI less than 5 , versus $5 \%$ in the normal AFI group.

NICU admissions were much higher $(84.84 \%)$ in patients with AFI $<=5$ than the patients with AFI between 6 and $24(69.30 \%)$.

\section{CONCLUSION}

In the presence of oligohydramnios, the rates of LSCS due to foetal distress, the occurrence of low Apgar score and of low birth weight are higher than in Patients with normal liquor at term. However, there was no difference in the perinatal outcome in terms of meconium staining.
The percentage of NICU admissions within 24 hours was much higher in the presence of oligohydramnios. Thus, measuring the amniotic fluid index at term can be helpful in the prediction of perinatal outcome.

\section{Funding: No funding sources}

Conflict of interest: None declared

Ethical approval: The study was approved by the Institutional Ethics Committee

\section{REFERENCES}

1. Singhal SR, Gupta R, Sen J. Low amniotic fluid index as a predictor of adverse perinatal outcome $\hat{a}$ An Indian perspective. Clin Mother Child Health. 2015;2015.

2. Chamberlain PF, Manning FA, Morrison I, Harman $\mathrm{CR}$, Lang CR. The relationship of marginal and decreased amniotic fluid volumes to perinatal outcome. Am J Obstet Gynecol. 1984;150(3):2459.

3. Nageotte MP, Towers CV, Asrat T, Freeman RK. Perinatal outcome with the modified biophysical profile. Am J Obstet Gynecol. 1994;170(6):1672-6.

4. Gumus II, Koktener A, Turhan NO. Perinatal outcomes of pregnancies with borderline amniotic fluid index. Arch Gynecol Obstet. 2007;276(1):17-9.

5. Griffin M, Attilakos G, Greenwood R, Denbow M. Amniotic fluid index in low risk, post-dates pregnancies. Fetal Diagnos Ther. 2009;26(4):212-5.

6. Robert W Bales, Chapter 3 Obstetrics, question number 76. Lipsky MS, King MS, Susman JL, Bales, Robert W, Hunsaker, Matthew L editors, Family Medicine Certification Review. Lippincott Williams and Wilkins; 2007:127-161.

7. Morris JM, Thompson K, Smithey J, Gaffney G, Cooke I, Chamberlain $\mathrm{P}$, et al. The usefulness of ultrasound assessment of amniotic fluid in predicting adverse outcome in prolonged pregnancy: a prospective blinded observational study. Int J Obstet Gynaecol. 2003;110(11):989-94.

8. Phelan JP, Ahn MO, Smith CV, Rutherford SE, Anderson E. Amniotic fluid index measurements during pregnancy. J Reprod Med. 1987;32:601-4.

9. Chauhan SP, Sanderson M, Hendrix NW, Magann EF, Devoe LD. Perinatal outcome and amniotic fluid index in the antepartum and intrapartum periods: a meta-analysis. Am J Obstet Gynecol. 1999;181(6):1473-8.

10. Locatelli A, Vergani P, Toso L, Verderio M, Pezzullo JC, Ghidini A. Perinatal outcome associated with oligohydramnios in uncomplicated term pregnancies. Arch Gynecol Obstet. 2004;269(2):1303.

11. Morris JM, Thompson K, Smithey J, Gaffney G, Cooke I, Chamberlain $\mathrm{P}$, et al. The usefulness of ultrasound assessment of amniotic fluid in predicting adverse outcome in prolonged pregnancy: a prospective blinded observational study. Br J Obstet Gynaecol. 2003;110(11):989-94. 
12. Rutherford SE, Phelan JP, Smith CV, Jacobs NA. The four-quadrant assessment of amniotic fluid volume: an adjunct to antepartum fetal heart rate testing. Obstet Gynecol. 1987;70(3):353-6.

13. Baron C, Morgan MA, Garite TJ. The impact of amniotic fluid volume assessed intrapartum on perinatal outcome. Am J Obstet Gynecol. 1995;173(1):167-74.

14. Sarno AP, Ahn MO, Brar HS, Phelan JP, Platt LD. Intrapartum Doppler velocimetry, amniotic fluid volume, and fetal heart rate as predictors of subsequent fetal distress. Am J Obstet Gynecol. 1989;161:1508-14.

15. Sarno AP, Ahn MO, Phelan JP. Intrapartum amniotic fluid volume at term; association of ruptered membranes, oligohydramnios and increased fetal risk. J Reprod Med. 1990;35:719-23.
16. Robson SC, Crawford RA, Spencer JAD, Lee A. Intrapartum amniotic fluid index and its relationship to fetal distress. Am J Obstet Gynecol. 1992;166:7882.

17. Voxman EG, Tran S, Wing DA. Low amniotic fluid index as a predictor of adverse perinatal outcome. $\mathbf{J}$ Perinatol. 2002;22(4):282-5.

18. Grubb DK, Paul RH. Amniotic fluid index and prolonged antepartum fetal heart rate decelerations. Obstet Gynecol. 1992;79(4):558-60.

Cite this article as: Dobariya $\mathrm{BH}$, Jani SA, Desai AN. Relationship between the amniotic fluid index at term and the perinatal outcome. Int J Reprod Contracept Obstet Gynecol 2020;9:2788-91. 